\title{
Assimilation of MIPAS observations using a three-dimensional global chemistry-transport model
}

\author{
By F. BAIER ${ }^{1 *}$, T. ERBERTSEDER ${ }^{1}$, O. MORGENSTERN ${ }^{2}$, M. BITTNER $^{1}$ and G. BRASSEUR ${ }^{3}$ \\ ${ }^{1}$ Deutsches Zentrum für Luft- und Raumfahrt, Deutsches Fernerkundungsdatenzentrum, Germany \\ ${ }^{2}$ Centre for Atmospheric Chemistry, Cambridge University, UK \\ ${ }^{3}$ Max-Planck-Institut für Meteorologie, Hamburg, Germany
}

(Received 23 May 2005; revised 31 October 2005)

\section{SUMMARY}

MIPAS observations are assimilated using a modified version of the chemistry-transport model ROSE to derive consistent global chemical analyses of the stratosphere. Due to different retrieval schemes applied, available MIPAS datasets are expected to differ in quality and coverage. In this study we investigate the sensitivity of the data assimilation scheme to two different sample datasets. ENVISAT/MIPAS baseline observations of $\mathrm{H}_{2} \mathrm{O}$, $\mathrm{O}_{3}, \mathrm{HNO}_{3}, \mathrm{CH}_{4}, \mathrm{~N}_{2} \mathrm{O}$ and $\mathrm{NO}_{2}$, covering October-November 2003, are considered. Sequential assimilation is performed using an optimum interpolation scheme with error propagation. It is shown that all assimilated model species benefit significantly from observations. Results are analysed using observation minus first-guess error statistics and are additionally compared to UARS/HALOE data. Optimized assimilation parameters are derived using $\chi^{2}$ diagnostics. Two different MIPAS data products are examined: the European Space Agency operational product and the Institute for Meteorology Karlsruhe (IMK) scientific product. Assimilation results show some significant differences with respect to the dataset type used. For example, regions with increased stratospheric $\mathrm{H}_{2} \mathrm{O}$ concentrations near the tropical tropopause are only present when IMK data are applied. Both datasets are found to be well suited for global assimilation experiments to study the chemistry and dynamics of the middle atmosphere. istry

KEYwords: Chemical data assimilation Error analysis Satellite observations Stratospheric chem-

\section{INTRODUCTION}

In order to derive consistent global three-dimensional (3D) chemical analyses from asynoptic and inhomogeneously distributed remote-sensing observations, sequential assimilation into chemistry-transport models (CTMs) has been successfully demonstrated by several former studies (e.g. Khattatov et al. 2000; Chipperfield et al. 2002; El Amraoui et al. 2004). Giving global coverage within several days, instruments on polar orbiting satellites are in general well suited for providing substantial information on the variability of chemical species within the stratosphere. To further analyse atmospheric processes (e.g. ozone depletion), optimal combination of models and observations is essential.

The Michelson Interferometer for Passive Atmospheric Sounding (MIPAS; Fischer and Oelhaf 1996) was launched aboard the European Environmental Satellite (ENVISAT) in March 2002. It performs global limb measurements in the near- to midinfrared and allows retrieval of temperature, pressure and trace-gas profiles of the middle atmosphere and upper troposphere (http://envisat.esa.int/instruments/mipas). Besides the operational European Space Agency (ESA) standard products (Carli et al. 2004) that focus on rapid processing of all observations, scientific off-line products are available. Depending on the trace-gas retrieval process applied, they show significant differences in quality and coverage. For this study we use data from the Institute for Meteorology Karlsruhe (IMK; Glatthor et al. 2005) for comparison with the standard ESA product.

The quality of data assimilation results strongly depends on the chemical characteristics of species observed (e.g. chemical time constants). The final analysis will

\footnotetext{
* Corresponding author: German Aerospace Centre, D-82234 Wessling, PO Box 1116, Germany.

e-mail: Frank.Baier@dlr.de
}

(c) Royal Meteorological Society, 2005. 
not be consistent if inadequate information is assimilated, e.g. if key species or error parameters are missing. In particular, information on the errors of remote-sensing data is often not sufficient for optimal assimilation. Therefore empirical adjustments and parametrizations are prerequisites (e.g. Khattatov et al. 2000).

Unlike variational assimilation schemes (e.g. Errera and Fonteyn 2001), the sequential method corrects the model first guess whenever observations are available. For a rigorous error treatment, giving non-biased statistically optimum results, Kalman-filterbased methods are principally well suited (Ménard et al. 2000). However, to reduce computational costs, approximations to the original formulation are necessary (Khattatov et al. 2000). Based on the CTM ROSE/DLR, we use a sequential assimilation scheme with optimum interpolation of first guess minus observation residuals and propagation of model errors (i.e. only the diagonal elements of the fully-fledged background covariance matrix are processed). Isotropic background correlations are parametrized using constant horizontal scale lengths (e.g. Riishøjgaard 1998). Vertical covariances are calculated from the averaging kernels used for the retrieval process and delivered with the MIPAS datasets.

This paper is structured as follows: we will first give a brief description of the different MIPAS datasets used in this study. The current version of the CTM ROSE/DLR is outlined in section 3 . The sequential assimilation scheme is described in section 4 with a focus on the set-up of assimilation parameters. (More details are given in the appendix.) Section 5 follows with a discussion of results using $\chi^{2}$ and observation minus first guess (OMF) error diagnostics, a comparison of assimilation results with Halogen Occultation Experiment (HALOE) observations, and our findings on typical zonal mean distributions of $\mathrm{H}_{2} \mathrm{O}, \mathrm{O}_{3}$ and $\mathrm{CH}_{4}$ for November 2003 are discussed. We close with a brief discussion (section 6).

\section{DATA}

The MIPAS instrument is a high-resolution atmospheric limb sounder aboard ESA's ENVISAT launched in March 2002 and operating in a sun-synchronous orbit. It aims at global and simultaneous measurements of the chemical composition of the middle atmosphere and upper troposphere. By means of sounding the earth's limb in the midinfrared, it gathers emission spectra during night and daytime conditions. Nearly global coverage is achieved within three days. Based on the analysis of emission features, profiles of temperature, pressure and a multitude of trace gases can be obtained with a maximum vertical resolution of $3 \mathrm{~km}$ and a horizontal averaging along the line of sight of approximately $400 \mathrm{~km}$ (Stiller et al. 2002). For a detailed description of the MIPAS trace-gas retrieval as applied by ESA and IMK, the reader is referred to Ridolfi et al. (2000), Steck and von Clarmann (2001), Carli et al. (2004), and references therein. Since the operational start of MIPAS, extensive calibration and validation campaigns have been carried out on emission spectra and trace-gas profiles (Snoeij et al. 2004 and references therein). For example, comparisons of MIPAS observations to collocated HALOE and Stratospheric Aerosol and Gas Experiment (SAGE II) measurements (Bracher et al. 2004) show in general good correspondence for the middle stratosphere, with higher deviations below $20 \mathrm{~km}$ altitude. Typical r.m.s. errors for $\mathrm{O}_{3}$ are found to be within 5 and $15 \%$. Corresponding errors for $\mathrm{H}_{2} \mathrm{O}, \mathrm{CH}_{4}$ and $\mathrm{NO}_{2}$ are considerably higher with maximum values between $25 \%$ and $35 \%$. Significant biases are found for all standard species, mostly positive about $10 \%$. For the ESA operational products, a significant scatter is present in the $\mathrm{O}_{3}, \mathrm{CH}_{4}$ and $\mathrm{N}_{2} \mathrm{O}$ profiles. MIPAS profiles seem to degrade rapidly below $15 \mathrm{~km}$ altitude. 
For this study we use the IMK dataset MIPAS-E v2 (hereafter MIMK) for October and November 2003 (see Glatthor et al. 2005 for $\mathrm{O}_{3}, \mathrm{CH}_{4}, \mathrm{~N}_{2} \mathrm{O}$; Funke et al. 2005 for $\mathrm{NO}_{2}$; Milz personal communication for $\mathrm{H}_{2} \mathrm{O}$; Mengistu Tsidu et al. 2005 for $\mathrm{HNO}_{3}$ ) and the corresponding ESA operational level 2 dataset v4.61 (hereafter MESA; Ceccherini and Ridolfi 2002; Carli et al. 2004; Ceccherini 2004). For comparability reasons, we use only the baseline observations of $\mathrm{O}_{3}, \mathrm{H}_{2} \mathrm{O}, \mathrm{CH}_{4}, \mathrm{~N}_{2} \mathrm{O}, \mathrm{NO}_{2}$ and $\mathrm{HNO}_{3}$. It should be mentioned that profiles of $\mathrm{NO}, \mathrm{ClONO}_{2}$ and $\mathrm{N}_{2} \mathrm{O}_{5}$ are also available from IMK. For this study only stratospheric data are used. The stratosphere is therefore defined by potential vorticity values greater than $2 \mathrm{PVU}\left(1 \mathrm{PVU}=10^{-6} \mathrm{~K} \mathrm{~m}^{2} \mathrm{~kg}^{-1} \mathrm{~s}^{-1}\right)$ or potential temperature above $380 \mathrm{~K}$.

While MIMK observations are more homogeneously distributed with respect to latitude and altitude, corresponding MESA observations show a better coverage of the upper stratosphere and lower mesosphere. The datasets also differ in temporal coverage. MESA observations cover the whole time period considered, with some days missing mainly during October 2003. For MIMK data there are two short gaps in October and November. There are no MIMK data available at all after 12 November 2003.

Both datasets give a good coverage of the middle atmosphere between 10 and $60 \mathrm{~km}$ altitude, which is the focus of this paper. MIMK-retrieved trace-gas profiles use a fixed vertical grid with $1 \mathrm{~km}$ step size. Each species' profile is provided with its own height-dependent vertical resolution. MESA retrievals are characterized by a variable vertical step size between 3 and $6 \mathrm{~km}$. The vertical resolution of MESA profiles can be derived from the averaging kernel matrix accompanying the data, which depends on species, latitude, height and season. Depending on the species considered, the vertical resolution of MESA data shows in general a weaker variability than the corresponding MIMK resolution. MIMK $\mathrm{CH}_{4}$ and $\mathrm{N}_{2} \mathrm{O}$ resolutions are significantly reduced in the lower stratosphere, while the MESA $\mathrm{N}_{2} \mathrm{O}$ vertical resolution is reduced in the upper stratosphere and lower mesosphere. The $\mathrm{MIMK} \mathrm{H}_{2} \mathrm{O}$ vertical resolution decreases particularly within the lower tropical stratosphere, where the corresponding MESA $\mathrm{H}_{2} \mathrm{O}$ resolution shows also a reduction, but to a lesser extent.

\section{CHEMISTRY-TRANSPORT MODEL ROSE/DLR}

For the sequential assimilation of MIPAS observations, as described in section 4, the DLR (German Aerospace Centre) version of the 3D global CTM NCAR-ROSE is applied (hereafter ROSE/DLR). The original model is described in detail in Rose and Brasseur (1989) and Granier and Brasseur (1991). ROSE/DLR is based on a modified and improved version of Marsh et al. (2001) with focus on stratospheric chemistry. The model covers the relevant stratospheric gas-phase chemical processes and heterogeneous processes on sulphuric acid aerosols. Heterogeneous processes on polar stratospheric clouds (PSCs) are calculated using an Ice-NAT* scheme as in Chipperfield (1999).

The chemical rate constants and cross-sections are taken from Sander et al. (2003). Photolysis rates are derived from a look-up table depending on zenith angle, the ozone column above and altitude. The chemical rate equations are solved considering the reactivity of stratospheric species. The rather long-lived ones, e.g. $\mathrm{HNO}_{3}$ and $\mathrm{N}_{2} \mathrm{O}_{5}$, are treated with a semi-implicit Gauss-Seidel solver. The fast-reacting species within the $\mathrm{HO}_{x}, \mathrm{NO}_{x}, \mathrm{ClO}_{x}, \mathrm{O}_{x}$ and $\mathrm{BrO}_{x}$ families are solved fully implicitly using NewtonRaphson iteration. $\mathrm{O}(1 \mathrm{D})$ is determined by considering the photochemical equilibrium state for the very short-lived species (e.g. $\mathrm{ClO}, \mathrm{NO}, \mathrm{HO}, \mathrm{BrO}$ ). The basic chemical time step is one hour. It is reduced adaptively to fulfil convergence.

* Nitric acid trihydrate. 
All species are transported using the Lin and Rood finite-volume advection scheme (Lin and Rood 1996). Wind and temperature fields are derived from 24-hour UK Met Office analyses which are available from ground up to $0.1 \mathrm{hPa}$ (Swinbank and O'Neill 1994). This dataset defines a consistent synoptic state using satellite-based temperature soundings and radiosonde observations assimilated in a global circulation model.

For this study ROSE/DLR consists of a $3.75^{\circ} \times 2.5^{\circ}$ longitude-latitude spherical grid on $43 \log$-pressure levels between 0 and approximately $56 \mathrm{~km}$ altitude, resulting in a vertical step size of $1.3 \mathrm{~km}$. Within the model's troposphere, ozone is relaxed to 2D SOCRATES data (Brasseur et al. 1995) with a time-scale of 10 days. The tropopause is therefore defined by a potential vorticity of $2 \mathrm{PVU}$ or a potential temperature of $380 \mathrm{~K}$ for the lower latitudes. All other species are prescribed by SOCRATES values at the model's upper and lower boundaries. The CTM is initialized with data from the 2D SOCRATES model corresponding to October conditions.

\section{DATA ASSIMILATION}

The NCAR-ROSE CTM has been used for assimilation of satellite data in several previous studies. Levelt et al. (1998) studied the performance of a simple optimal interpolation (OI) scheme using Upper-atmosphere Research Satellite (UARS) Microwave Limb Sounder (MLS) ozone observations. Ménard et al. (2000) proposed several modifications to the extended Kalman filter to reduce numerical errors. They analysed different aspects of the covariance calculus and its influence on assimilation results. Khattatov et al. (2000) applied a similar scheme using parametrized covariances. It consists primarily of OI with error propagation of analysis variances. They used the same forward model for both tracers and variances. This set-up has been applied successfully for different CTMs and input data (e.g. Chipperfield et al. 2002; El Amraoui et al. 2004). We will use a related set-up for the sequential assimilation of MIPAS chemical data.

For the observational error we use the random errors (precision) as delivered with the datasets. It is well known that these errors are in general not sufficient for assimilation. As in Khattatov et al. (2000), a representativeness error $\mathbf{R}$ is therefore added. $\mathbf{R}$ consists only of the diagonal components (variances). The initial analysis error variances, $\sigma_{i i}^{2}$, and the model error growth rates, $\epsilon$, were tuned as described in section 5 depending on dataset type, latitude and species. The correlation part of background covariances $\mathbf{B}$ is parametrized by Gaussian functions depending on the local Euclidian grid-point distances. The horizontal scale is set to $1000 \mathrm{~km}$ and the vertical scale to $1.3 \mathrm{~km}$, i.e. the vertical model step size. We will use $\chi^{2}$ diagnostics (Khattatov et al. 2000; Chipperfield et al. 2002; Fierli et al. 2002; El Amraoui et al. 2004) to derive improved parameter sets for $\sigma_{i i}^{2}, \mathbf{R}$, and $\epsilon$ for both MIMK and MESA data (section 5).

Depending on the observing geometry, the sample rate and the retrieval scheme used, the effective resolution can vary considerably. This has to be considered for the interpolation from model grid points to observations. The horizontal interpolation uses a linear weighting with a fixed horizontal box size of $1000 \mathrm{~km}$. For the vertical interpolation, the full width half maximum (FWHM) is used as a measure of the vertical resolution. The latter is derived from the averaging kernels as provided by MESA which depend on species, latitude and season. MIMK gives the respective FWHM values for each individual profile and species. See the appendix for further details on the assimilation scheme. 
TABLE 1. MOdel ERror growth RATE PARAMETER, $\epsilon\left(\mathrm{hr}^{-1}\right)$, FOR DIFFERENT ASSIMILATED SPECIES

\begin{tabular}{cccccc}
\hline $\mathrm{H}_{2} \mathrm{O}$ & $\mathrm{O}_{3}$ & $\mathrm{HNO}_{3}$ & $\mathrm{CH}_{4}$ & $\mathrm{~N}_{2} \mathrm{O}$ & $\mathrm{NO}_{2}$ \\
\hline 0.007 & 0.007 & 0.020 & 0.007 & 0.014 & 0.020 \\
\hline
\end{tabular}

\section{RESULTS}

\section{(a) $\chi^{2}$ and $O M F$ diagnostics}

Global mean $\chi^{2}$ and OMF values were calculated to check the consistency of assimilation parameters and investigate the influence of assimilated observations on the system. Results were also used to tune model error growth rates and representativeness errors. In the following $\mathbf{y}, \mathbf{x}$ and $\mathbf{H}$ depict observations, model first-guess values and the (linear) interpolation operator, respectively:

$$
\begin{gathered}
\mathrm{OMF} \equiv(\mathbf{y}-\mathbf{H x}) \\
\chi^{2}=\frac{1}{N} \sum \mathrm{OMF}^{\mathrm{T}}\left(\mathbf{H B H} \mathbf{H}^{\mathrm{T}}+\mathbf{O}+\mathbf{R}\right)^{-1} \mathrm{OMF} .
\end{gathered}
$$

$\mathbf{B}, \mathbf{R}$ and $\mathbf{O}$ indicate the background-error covariance matrix and the corresponding representativeness and observational error variances. We will use the analysis error as a synonym for the variance component of the diagnosed background-error covariance (see appendix). The sum in Eq. (2) consists of at least all $N$ observations within a profile and a latitude band. Ideally, within Gaussian bias-free statistics, $\chi^{2}$ values are expected to $b e \simeq 1$, i.e. OMF error residuals and a priori errors are comparable in size. Initially, systematic differences between model and observations will give exceptionally high OMF and $\chi^{2}$ values. If representativeness and background errors are adequate to the problem, then $\chi^{2}$ will converge to identity during the course of assimilation.

Initially, relative representativeness errors were all set to $10 \%$ of corresponding model values, while the model error growth rate, $\epsilon$, was set to $0.014 \mathrm{hr}^{-1}$ for all species as in Khattatov et al. (2000). It was found that in this case the resulting $\chi^{2}$ values were much too high. As discussed by Ménard and Chang (2000), $\chi^{2}$ is mainly controlled by $\mathbf{R}$ and $\epsilon$. Therefore, adjustments to $\mathbf{R}$ and $\epsilon$ parameters were applied as follows: a first assimilation run was performed to derive latitudinal-dependent temporal mean $\chi^{2}$ values; these were then used as a correction factor for the representativeness error and the initial background error. The first 10 days of the analysis were not considered, to allow the model to adjust to observations. Next, corrections were applied to $\epsilon$ only. By reducing $\epsilon$ values for $\mathrm{H}_{2} \mathrm{O}$ and $\mathrm{CH}_{4}$, corresponding $\chi^{2}$ values were increased. In the case of $\mathrm{HNO}_{3}$ and $\mathrm{NO}_{2}, \chi^{2}$ values were decreased by increasing $\epsilon$.

Table 1 shows the final $\epsilon$ settings used for all the following assimilation experiments. Compared to other strategies (e.g. El Amraoui et al. 2004), our approach has the advantage of giving improved parameters using a single assimilation experiment only. In principle, the results can be improved further by recursive application of the $\chi^{2}$ diagnostics.

By definition, the resulting corrected representativeness errors depend on latitude (see Fig. 1). Most error values derived in this way correspond to a relative error between 5 and $20 \%$. Relatively high values are found for MESA and MIMK $\mathrm{HNO}_{3}$ in the subtropics and high latitudes. Corresponding $\mathrm{N}_{2} \mathrm{O}$ errors show maximum values in the tropics and high southern latitudes. For $\mathrm{NO}_{2}$, a strong increase of representativeness errors is derived for high northern latitudes which is especially significant in the case of 

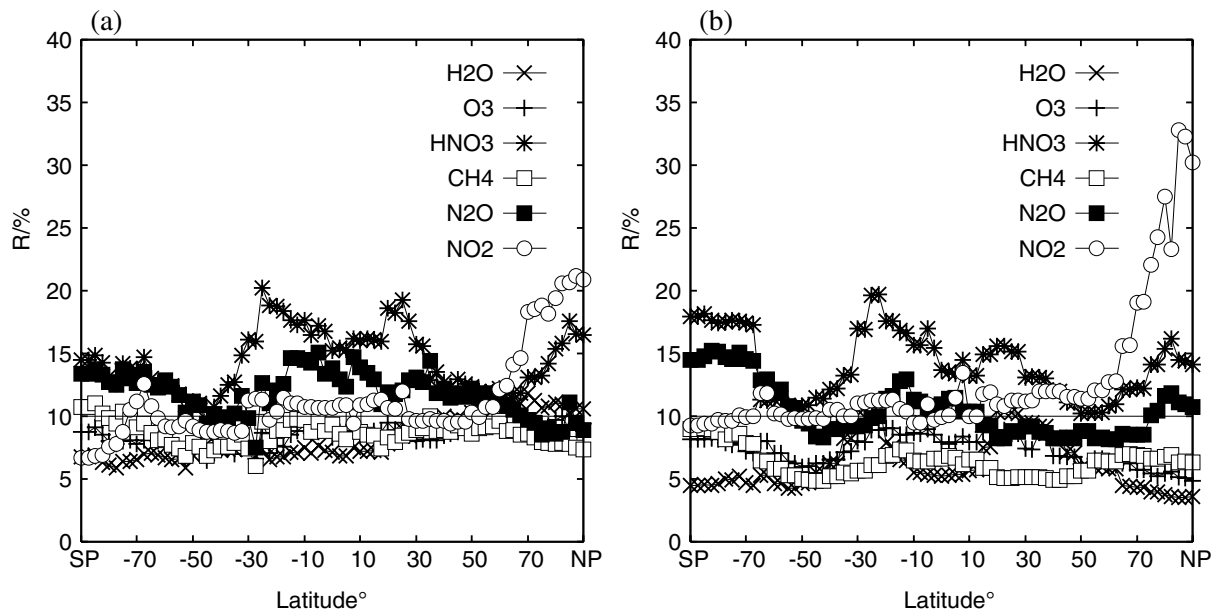

Figure 1. Latitudinal distribution of the mean representativeness errors (\%) derived for (a) MESA and (b) MIMK datasets. The initial relative error of $10 \%$ is adjusted according to $\chi^{2}$ results of the initial assimilation experiments covering 31 October to 20 November 2003 (see text).
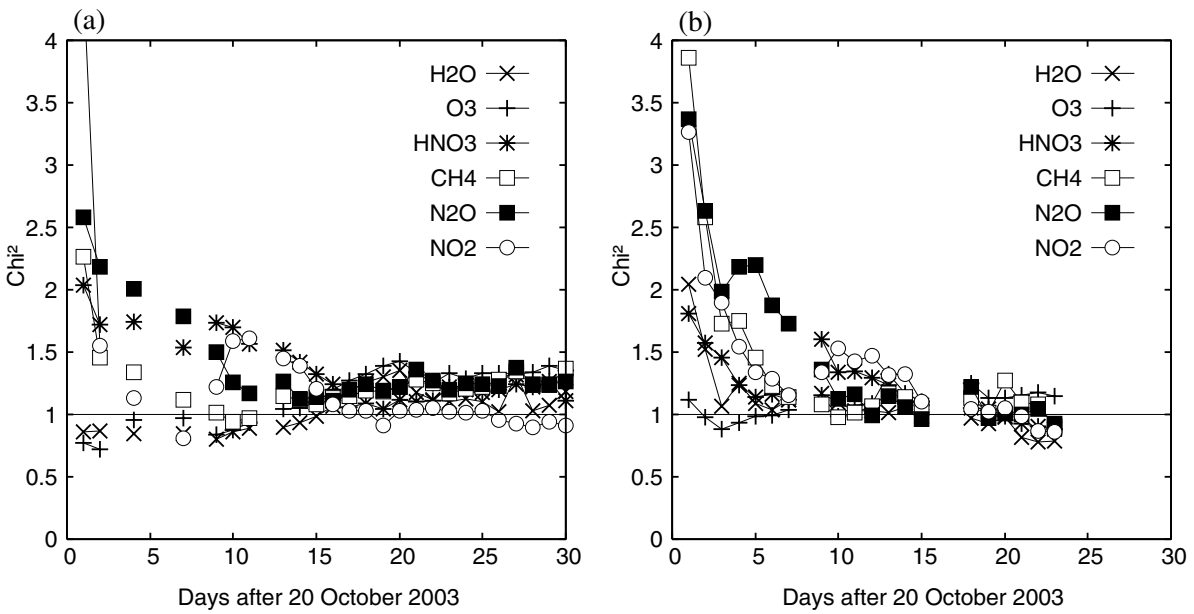

Figure 2. Time series of global mean $\chi^{2}$ values for the final assimilation experiment using (a) MESA and (b) MIMK datasets covering 21 October to 20 November 2003.

MIMK data. This increase of $\mathrm{NO}_{2}$ errors can be clearly related to the solar proton events in late October and early November 2003 (Degenstein et al. 2005).

Figure 2 shows $\chi^{2}$ results for the six standard species of both MESA and MIMK data, during the course of assimilation. As can be seen from the plots, initial $\chi^{2}$ values are in general too high but decrease considerably within the first two weeks. At the end of the assimilation period, values deviate from unity by no more than $50 \%$. Some improvements could still be achieved by fine-tuning error growth rates for each dataset used. However, since the focus of this paper is on the comparison of different datasets, no further adjustments of assimilation parameters were applied.

In order to evaluate the performance of the assimilation system in more detail, relative OMF and analysis errors were analysed separately. In general, correspondence 
TABLE 2. HALOE COMPARISON RESULTS

\begin{tabular}{lrrrrrrrr}
\hline & \multicolumn{2}{c}{ MESA 2003} & & \multicolumn{2}{c}{ MIMK 2003 } & & \multicolumn{2}{c}{ Reference } \\
\cline { 2 - 3 } \cline { 8 - 9 } Species & Bias & r.m.s. & & Bias & r.m.s. & & Bias & r.m.s. \\
\hline $\mathrm{O}_{3}$ & -0.54 & 11.89 & & -3.48 & 13.72 & & -0.89 & 16.12 \\
$\mathrm{H}_{2} \mathrm{O}$ & 3.30 & 16.18 & & 4.83 & 14.87 & & -13.09 & 23.75 \\
$\mathrm{NO}_{x}$ & -3.48 & 36.73 & & 4.93 & 33.21 & & -7.63 & 45.30 \\
$\mathrm{CH}_{4}$ & 7.98 & 16.82 & & 13.36 & 21.26 & & 12.50 & 28.29 \\
$\mathrm{HCl}$ & -6.37 & 23.83 & & -5.47 & 23.18 & & -6.08 & 23.50 \\
\hline
\end{tabular}

Results of analysis minus HALOE comparisons showing the mean relative error values (\%) for the assimilation experiments using MESA and MIMK data from 21 October to 20 November 2003. The reference columns show results without assimilation of MIPAS data. See text for more details.

between OMF and analysis errors is good. As can be anticipated from the $\chi^{2}$ analyses, higher deviations are found for $\mathrm{HNO}_{3}, \mathrm{~N}_{2} \mathrm{O}$ and $\mathrm{NO}_{2}$. In the case of $\mathrm{HNO}_{3}$ and $\mathrm{N}_{2} \mathrm{O}$, the derived representativeness errors are probably overestimated, resulting in analysis errors which are too high. As further investigations show, the respective $\mathrm{N}_{2} \mathrm{O} \chi^{2}$ analysis is strongly influenced by OMF errors in the upper stratosphere. For $\mathrm{HNO}_{3}, \mathrm{OMF}$ errors show maximum values within the tropical lower stratosphere. $\mathrm{HNO}_{3}$ errors also correlate strongly with respective $\mathrm{NO}_{2}$ errors in the upper northern stratosphere.

For $\mathrm{NO}_{2}$, rather high OMF error values are expected due to its short photochemical time constant and the corresponding increase of representation errors, i.e. large times and distances between model and observations (Bracher et al. 2005). Differences are most pronounced when observed $\mathrm{NO}_{2}$ values increase due to exceptional strong solar proton events (Degenstein et al. 2005). The model is intrinsically inadequate to simulate the observed $\mathrm{NO}_{2}$ peak values. This can be attributed to the absence of any $\mathrm{NO}_{2}$ source within the model domain that can mimic the effects of solar particle radiation. However, decreasing $\mathrm{NO}_{2} \mathrm{OMF}$ errors at the end of the assimilation period clearly indicates that the assimilation in general benefits from the $\mathrm{NO}_{2}$ observations.

\section{(b) Comparisons with HALOE observations}

To give an independent estimate of the final analysis quality, comparisons against independent measurements are necessary. Therefore, we now discuss comparisons with HALOE observations. We use HALOE version 19 data available for October and November 2003 (http://haloedata.larc.nasa.gov) for sunrise and sunset conditions. Observations are limited to the middle northern latitudes and two latitude bands near $70^{\circ} \mathrm{S}$ and $30^{\circ} \mathrm{S}$. Approximately two weeks are covered by observations in October and also in November 2003. Only data above the tropopause (defined by 2 PVU) are considered. Because of the strong scatter of HALOE $\mathrm{NO}_{x}$ observations above $1 \mathrm{hPa}$, such data were rejected.

Table 2 shows the mean analysis minus observation errors (biases) and the mean r.m.s. errors for the assimilation results using MESA and MIMK data. Corresponding results for the reference run without assimilation of MIPAS data are also given. Due to the general high zenith angle sensitivity of nitrous oxides, $\mathrm{NO}_{x}\left(=\mathrm{NO}_{2}+\mathrm{NO}\right)$ is considered instead of single NO species. In all cases, biases are much smaller than the mean r.m.s. errors. Maximum r.m.s. errors are found for $\mathrm{NO}_{x}$ for both MIMK and MESA assimilation experiments. With the exception of $\mathrm{HCl}$ (not assimilated), relative improvements compared to the reference run reach $40 \%$. Only $\mathrm{MIMK} \mathrm{O}_{3}$ and $\mathrm{CH}_{4}$ mean biases increase slightly relative to HALOE. 

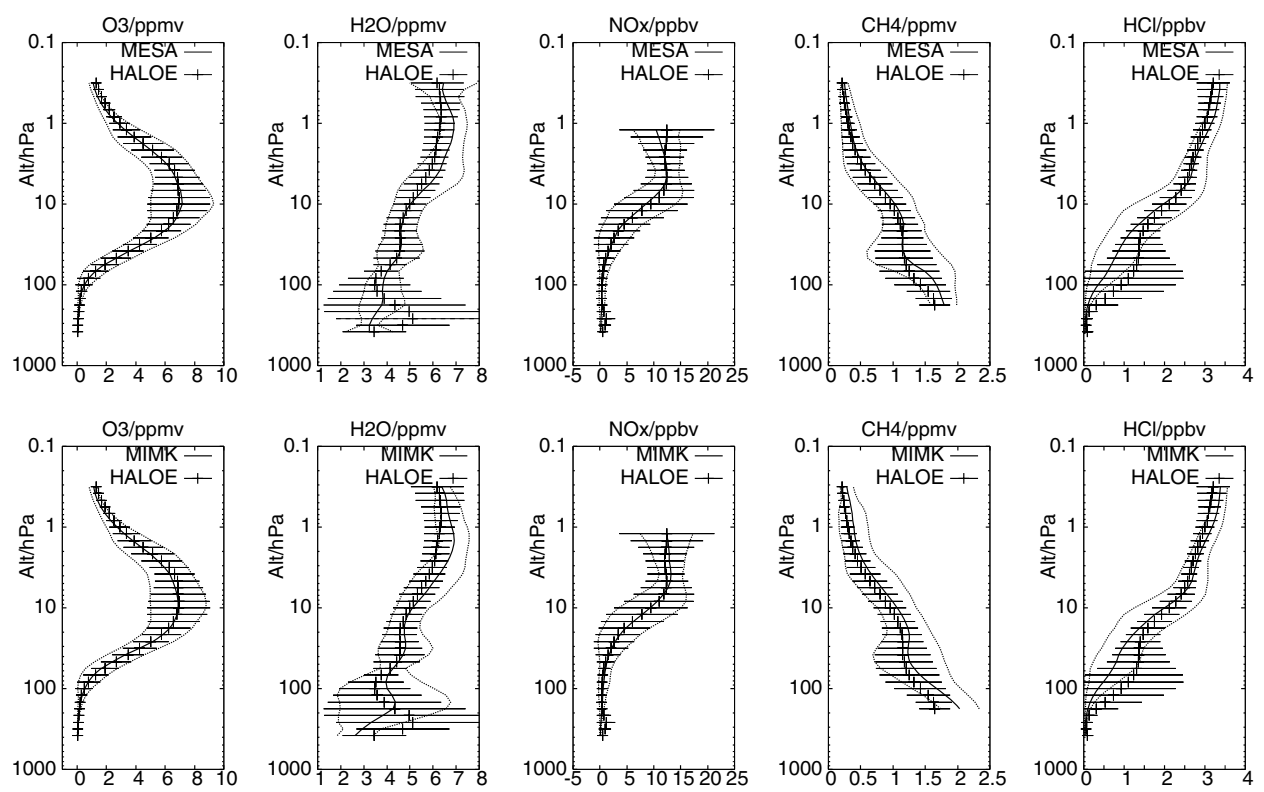

Figure 3. Mean collocated profiles of $\mathrm{O}_{3}, \mathrm{H}_{2} \mathrm{O}, \mathrm{NO}_{x}, \mathrm{CH}_{4}$ and $\mathrm{HCl}$ as observed by $\mathrm{HALOE}$ (vertical bars) and by (upper row) MESA and (lower row) MIMK analyses (both central solid curves) for 21 October to 20 November 2003. Horizontal bars (HALOE) and outer curves (MESA/MIMK) indicate the mean standard deviation at each model level.

Figure 3 shows the altitude dependency of the mean mixing ratio profiles as observed by HALOE compared with collocated assimilation results. Differences are within respective standard deviations (i.e. variability between single profiles). Only minor differences are found between MIMK and MESA assimilation results. In both cases, a positive bias for $\mathrm{H}_{2} \mathrm{O}$ (upper stratosphere) and $\mathrm{CH}_{4}$ (lower stratosphere) is visible. Above the ozone maximum, there is also a weak positive bias present especially in the MIMK results. In the case of the MIMK analysis, the $\mathrm{CH}_{4}$ bias extends well into the upper stratosphere. The positive $\mathrm{H}_{2} \mathrm{O}$ bias near $100 \mathrm{hPa}$ is more pronounced in the MIMK results. Below $100 \mathrm{hPa}$, both analyses underestimate $\mathrm{H}_{2} \mathrm{O}$ mixing ratios compared with HALOE observations. $\mathrm{HCl}$ mixing ratios are underestimated below $10 \mathrm{hPa}$ and overestimated in the mesosphere. Compared to results without assimilated MIPAS observations, $\mathrm{HCl}$ shows no improvements, as expected, while all other species clearly improve their mean values and standard deviations.

To summarize, comparison results are in general within the known accuracy ranges of HALOE observations $\left(\mathrm{O}_{3}\right.$, Brühl et al. 1996; $\mathrm{H}_{2} \mathrm{O}$, Harries et al. 1996; $\mathrm{CH}_{4}$, Park et al. 1996; $\mathrm{HCl}$, Russell III et al. 1996; $\mathrm{NO}_{2}, \mathrm{~N}_{2} \mathrm{O}$, Gordley et al. 1996). Our findings for $\mathrm{H}_{2} \mathrm{O}$ and $\mathrm{CH}_{4}$, showing an overall positive bias compared to HALOE, are consistent with HALOE comparisons against ATLAS2/ATMOS* measurements. HALOE HCl observations are known to give values which are too low in the stratosphere. Because our results show significantly lower $\mathrm{HCl}$ values than $\mathrm{HALOE}$ below $10 \mathrm{hPa}$, this hints at a general model problem. As indicated by strong scatter, HALOE $\mathrm{H}_{2} \mathrm{O}$ observations from below $100 \mathrm{hPa}$ are suspicious (e.g. due to cloud contamination). Keeping this in mind, the variability of MIMK results compares better with HALOE observations than the corresponding MESA results.

* Atmospheric Trace Molecule Spectroscopy. 
(a) MIPAS ESA H2O/ppmv NOV 52003
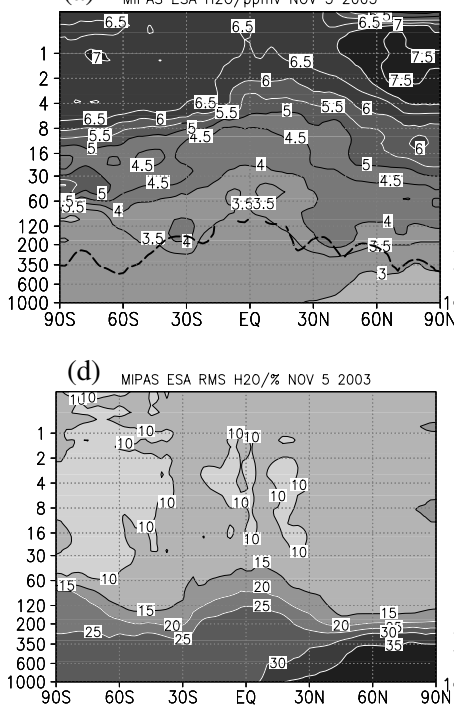

(b) MIPAS ESA 03/ppmv NOV 52003

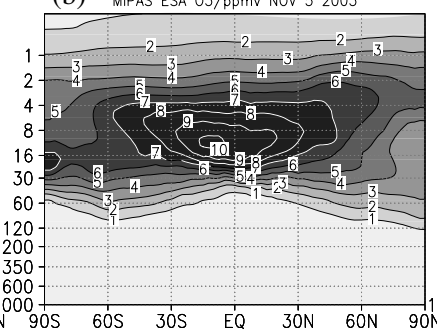

(e) MIPAS ESA RMS 03/\% NOV 52003

(c) MIPAS ESA CH4/ppmv NOV 52003

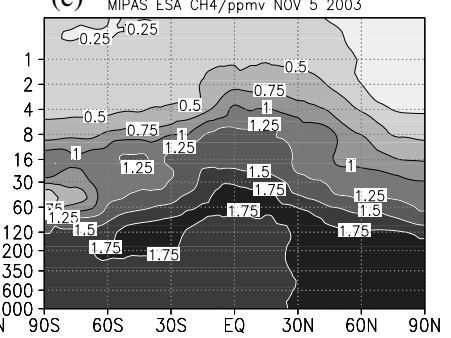

(f) MIPAS ESA RMS CH4/\% NOV 52003
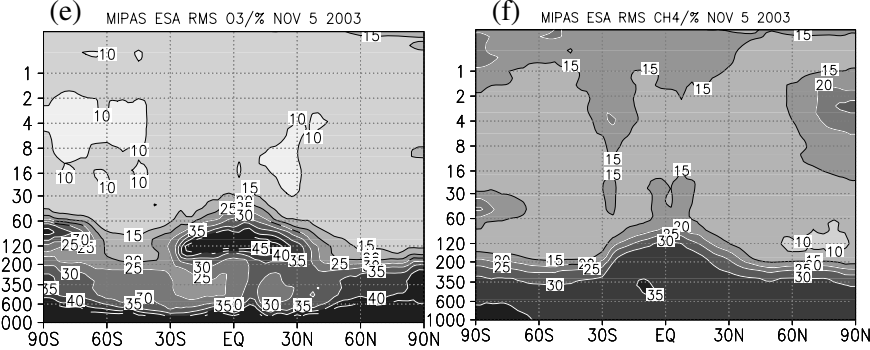

Figure 4. Zonal mean MESA analyses (ppmv) for (a) $\mathrm{H}_{2} \mathrm{O}$, (b) $\mathrm{O}_{3}$ and (c) $\mathrm{CH}_{4}$ for 5 November 2003, with corresponding r.m.s. analysis errors (\%) at (d), (e) and (f). In (a), the 2 PVU contour (dashed) denotes the tropopause. The vertical axes show altitude as pressure levels in $\mathrm{hPa}$.

(a) MIPAS IMK H20/ppmv NOV 52003

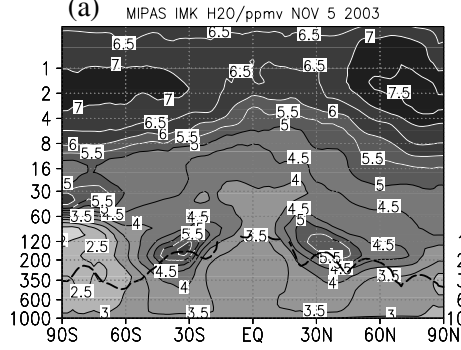

(b) MIPAS IMK 03/ppmv NOV 52003

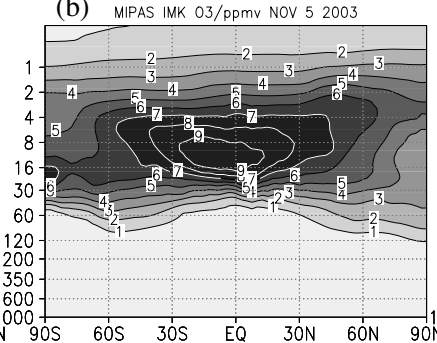

(c) MIPAS IMK CH4/ppmv NOV 52003

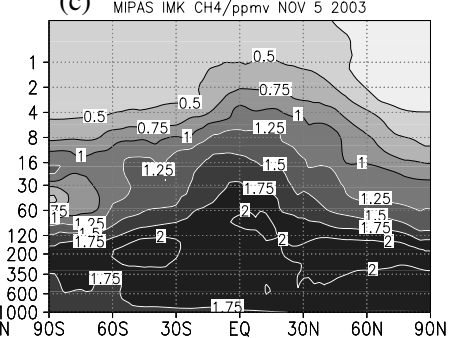

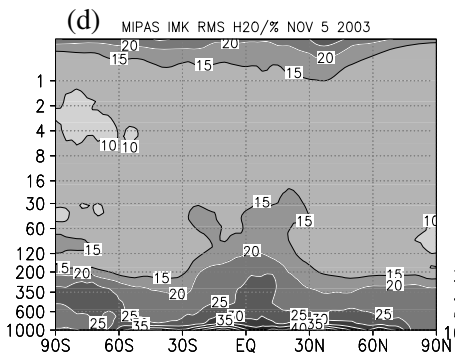

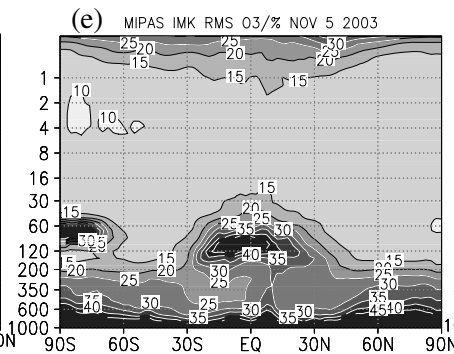

(f) MIPAS IMK RMS CH4/\% NOV 52003

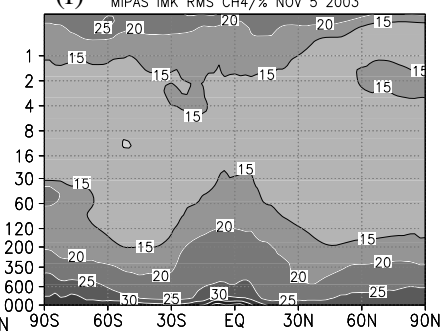

Figure 5. As Fig.4, but for MIMK analyses.

\section{(c) Zonal mean results}

In order to give an example of the general quality of the assimilation results, we finally examine the zonal mean analyses and zonal mean analysis errors for $\mathrm{H}_{2} \mathrm{O}, \mathrm{O}_{3}$ and $\mathrm{CH}_{4}$. Figures 4 and 5 show the distributions for 5 November 2003 using MIMK and MESA data, respectively. This date is well covered by both MESA and MIMK observations and lies in the centre of the 30-day assimilation period (see Fig. 2). 
Differences with respect to MESA and MIMK input data are small in general, except for two regions with increased $\mathrm{H}_{2} \mathrm{O}$ and $\mathrm{CH}_{4}$ mixing ratios near the tropical tropopause (indicated by the dashed line in $\mathrm{H}_{2} \mathrm{O}$ plots). These are only visible when MIMK data are assimilated. MESA and MIMK analysis errors are in general very similar, but differ significantly in some regions mainly due to different data coverage. In both cases, minimum relative error values are found between 60 and $1 \mathrm{hPa}$. Errors increase strongly where no observations are available. For the species shown, this is mainly true for the troposphere and the tropopause region. For the same reason, $\mathrm{HNO}_{3}, \mathrm{~N}_{2} \mathrm{O}$ and $\mathrm{NO}_{2}$ analysis errors (not shown) increase considerably in the upper stratosphere and lower mesosphere. MIMK analyses of $\mathrm{H}_{2} \mathrm{O}, \mathrm{O}_{3}$ and $\mathrm{CH}_{4}$ also show a strong increase of analysis errors above $1 \mathrm{hPa}$.

\section{DISCUSSION}

We have developed a sequential data assimilation scheme to derive an improved analysis of the chemical state from different MIPAS observational datasets for October and November 2003. Using the CTM ROSE/DLR, results clearly improve in all cases considered when the MIPAS standard species $\mathrm{H}_{2} \mathrm{O}, \mathrm{O}_{3}, \mathrm{HNO}_{3}, \mathrm{CH}_{4}, \mathrm{~N}_{2} \mathrm{O}$ and $\mathrm{NO}_{2}$ are assimilated. However, significant differences due to different coverage and quality of input data (MESA/MIMK) are evident. MESA data are processed within an operational environment with good temporal coverage in general, while MIMK data are only available for single episodes with more homogeneous spatial coverage and less scatter.

In order to strengthen the consistency of the analyses, results of $\chi^{2}$ diagnostics were employed to improve the initial background and representativeness errors. Improvements to model results without assimilation of MIPAS data were quantified by comparisons with HALOE observations. Results show an r.m.s. error reduction of up to $40 \%$ for the assimilated species. The positive influence of data assimilation is also found in the analysis error which significantly decreases where observations are available. At the end of October and again in early November 2003, observed $\mathrm{NO}_{x}$ concentrations increased rapidly in the mesosphere and upper stratosphere due to several solar proton events (Degenstein et al. 2005). This is evident as increased analysis errors in both MIMK and MESA $\mathrm{NO}_{2}$ results. Nevertheless, assimilation of $\mathrm{NO}_{x}$ species proves valuable, as shown by comparisons with HALOE.

Regarding the different datasets used, mean assimilation results are comparable with some exceptions: assimilation of MIMK data leads in particular to higher $\mathrm{H}_{2} \mathrm{O}$ mixing ratios in the lowermost stratosphere; two regions with increased $\mathrm{H}_{2} \mathrm{O}$ values near the tropical tropopause, covered both by MESA and MIMK data, show only up in the results with MIMK data; and, compared with HALOE observations, MIMK $\mathrm{CH}_{4}$ results show a strong positive bias throughout the stratosphere. In summary, both MIMK and MESA datasets are found to be well suited for global chemical data assimilation, when the special characteristics of each dataset are taken into account. The presented assimilation system contributes significantly in fulfilling the general objective to better monitor and study the chemical composition of the middle atmosphere.

\section{ACKNOWLEDGEMENTS}

We thank the reviewers for their constructive comments and helpful advice. ESA is acknowledged for providing the MIPAS Level 2 data within the ESA-AO project EVIVA. We are grateful to the Institute of Meteorology, Karlsruhe, for supply of MIPAS IMK data and for fruitful discussion. The Instituto de Astrofisica de Andalucia 
(CSIC) provided crucial data for the IMK $\mathrm{NO}_{2}$ retrieval. Further, we thank the German Ministry for Education and Research for funding HGF-ENVISAT (HGF/BMBFVernetzungsfonds) and the INVERT project (via grant 07ATF11). The UK Met Office and the HALOE team kindly provided the necessary meteorological and correlative data. We would also like to thank our colleagues from DLR D-PAC. We finally thank Anne Smith and Dan Marsh for providing the original NCAR-ROSE model code.

\section{APPENDIX}

\section{Assimilation scheme}

For this study an optimum interpolation scheme with propagation of analysis errors as in Khattatov et al. (2000) is used to correct the model first guess at each model time step. For a statistically viable weighting of model forecast and observations, background, $\mathbf{B}$, observational, $\mathbf{O}$, and representation, $\mathbf{R}$, error variances and covariances have to be specified. The statistically optimum analysis $\mathbf{x}^{\prime}$ can then be calculated from the model's first-guess state vector $\mathbf{x}$ and the observation vector $\mathbf{y}$ as follows (e.g. Daley 1991):

$$
\mathbf{x}^{\prime}=\mathbf{x}+\mathbf{B} \mathbf{H}^{\mathrm{T}}\left(\mathbf{H B H} \mathbf{H}^{\mathrm{T}}+\mathbf{O}+\mathbf{R}\right)^{-1}(\mathbf{y}-\mathbf{H x}) .
$$

The observation vector $\mathbf{y}$ holds all sampled observations within one profile. Interpolation from and to the neighbouring model grid points is performed using the forward interpolation operator $\mathbf{H}$. $\mathbf{H}$ comprises the product of a vertical and horizontal linear interpolation using vertical log-pressure and local Euclidian coordinates, respectively. Details regarding the application of MIPAS observations are given in section 4. No error correlations are used ( $\mathbf{R}$ and $\mathbf{O}$ matrixes are diagonal). Note that adding a representation error variance, $\mathbf{R}$, in fact increases the observational error. As discussed in section 4 , this is necessary to make the errors consistent. The $\mathbf{B}$ covariance matrix disperses the resulting corrections back to the model grid. It therefore must take the model's resolution and presumed uncertainty into account. With respect to the model's grid points, the matrix elements of $\mathbf{B}$ are modelled by Gaussian functions (e.g. Riishøjgaard 1998):

$$
B_{i j}=\sigma_{i i} \sigma_{j j} \exp \left(\frac{-d^{2}}{2 D^{2}}\right) \exp \left(\frac{-r^{2}}{2 R^{2}}\right),
$$

where $d, r$ and $D, R$ describe the horizontal and vertical distances between model grid points and scales respectively. $D$ and $R$ scales are set to $1000 \mathrm{~km}$ and $1.3 \mathrm{~km}$ (the model's vertical step size). $\sigma_{i i}^{2}$ and $\sigma_{j j}^{2}$ are the model's first-guess variances at grid points $i$ and $j$. For the analysis (A.1), error covariances are calculated as follows:

$$
\mathbf{E}=\mathbf{B}-\mathbf{B H}^{\mathrm{T}}\left(\mathbf{H B} \mathbf{H}^{\mathrm{T}}+\mathbf{O}+\mathbf{R}\right)^{-1} \mathbf{H B} .
$$

Only the diagonal components $E_{i i}$ (variances) are retained for the subsequent temporal error propagation. Variances of all observed species are then transported as quasitracers. We add a chemical correction using the change of mixing ratios $\mu_{i i}^{\prime} / \mu_{i i}$ due to model chemistry. Finally an error increment is added to mimic the model error increase (Ménard et al. 2000). In summary, the propagated analysis variance after one time step takes the form:

$$
\sigma_{i i}^{2} \doteq T\left(E_{i i}\right) \cdot \frac{\mu_{i i}^{\prime}}{\mu_{i i}}+\left(\epsilon \mu_{i i}\right)^{2},
$$

with $T$ describing the advection step and $\epsilon$ the error increase rate per hour (see section 4). The adjustable parameter $\epsilon$ and the initial variances $\sigma_{i i}^{2}$ are defined as prescribed in section 5(a). 


\section{REFERENCES}

El Amraoui, L., Ricaud, P.,

Urban, J., Théodore, B.,

Hauchecorne, A., Lauti, J.,

De La Noë, N., Guirlet, M.,

Le Flocjmoën, E.,

Murtagh, D., Dupuy, E.,

Frisk, U. and d'Andon, O. F.

Bracher, A., Sinnhuber, M.,

Rozanov, A. and Burrows, J. P.

Bracher, A., Bramstedt, K.,

Sinnhuber, M., Weber, M. and

Burrows, J. P.

Brasseur, G., Hitchman, M. H.,

Walters, S., Dymek, M.,

Falise, E. and Pirre, M.

Brühl, C., Drayson, S. R.,

Russell III, J. M.,

Crutzen, P. J.,

McInerney, J. M.,

Purcell, P. N., Claude, H.,

Gernandt, H., McGee, T. J.,

McDermid, I. S. and

Gunson, M. R.

Carli, B., Alpaslan, D., Carlotti, M., 2004

Castelli, E., Ceccherini, S.,

Dinelli, B. M., Dudhia, A.,

Flaud, J. M., Höpfner, M.,

Jay, V., Magnani, L.,

Oelhaf, H., Payne, V.,

Piccolo, C., Prosperi, M.,

Raspollini, P., Ridolfi, M.,

Remedios, J. and Spang, R.

Ceccherini, $\mathrm{S}$.

Ceccherini, S. and Ridolfi, M.

2002

Chipperfield, M. P.

1999

Chipperfield, M. P., Khattatov, B. V. 2002 and Lary, D. J.

Daley, R.

Degenstein, D. A., Lloyd, N. D., Bourassa, A. E.,

Gattinger, R. L. and

Llewellyn, E. J.

Errera, Q. and Fonteyn, D.

Fierli, F., Hauchecourne, A.,

Bekki, S., Théodore, B. and d'Andon, O. F.

Fischer, H. and Oelhaf, $\mathrm{H}$.

2004
Assimilation of Odin/SMR $\mathrm{O}_{3}$ and $\mathrm{N}_{2} \mathrm{O}$ measurements in a threedimensional chemistry transport model. J. Geophys. Res., 109, D22304, doi: 10.1029/2004JD004796

'Averaging kernels for MIPAS off-line level 2 retrievals'. IFAC Technical Note, Italian National Research Council, Prog. Doc. No.: IFAC-GA-2004-01-SC

'Averaging kernels for MIPAS near-real-time level 2 retrievals'. IFAC Technical Note, Italian National Research Council, Prog. Doc. No.: TN-IFAC-OST0201

Multiannual simulations with a three-dimensional chemical transport model. J. Geophys. Res., 104(D1), 1781-1805

Sequential assimilation of stratospheric chemical observations in a three-dimensional model. J. Geophys. Res., 107(D21), 4585, doi: 10.1029/2002JD002110

Atmospheric data analysis. Cambridge University Press, Cambridge, UK

Observations of mesospheric ozone depletion during the October 28, 2003 solar proton event by OSIRIS. Geophys. Res. Lett., 32, L03S11, doi: 10.1029/2004GL021521
Four-dimensional variational chemical data assimilation of CRISTA stratospheric measurements. J. Geophys. Res., 106, 12253-12265

Data assimilation of stratospheric ozone using a high-resolution transport model. Geophys. Res. Lett., 29(10), doi: 10.1029/2001GL014272

Remote sensing of vertical profiles of atmospheric trace constituents with MIPAS limb-emission spectra. Appl. Opt., 35(16), 2787-2796 
Funke, B., Lopez-Puertas, M., von Clarmann, T., Stiller, G. P., Fischer, H., Glatthor, N., Grabowski, U., Höpfner, M., Kellmann, S., Kiefer, M., Linden, A., Mengistu Tsidu, G., Milz, M., Steck, T. and Wang, D.-Y.

Glatthor, N., von Clarmann, T., Fischer, H., Funke, B., Grabowski, U., Höpfner, M., Kellmann, S., Kiefer, M., Linden, A., Milz, M., Steck, S., Stiller, G. P., Mengistu Tsidu, G. and Wang, D.-Y.

Gordley, L. L., Russell III, J. M., Mickley, L. J., Frederick, J. E., Park, J. H., Stone, K. A., Beaver, G. M.,

McInerney, J. M.,

Deaver, L. E., Toon, G. C.,

Murcray, F. J.,

Blatherwick, R. D.,

Gunson, M. R.,

Abbatt, J. P. D.,

Mauldin III, R. L.,

Mount, G. H., Sen, B. and

Blavier, J.-F.

Granier, C. and Brasseur, G.

Harries, J. E., Russell III, J. M., Tuck, A. F., Gordley, L. L., Purcell, P., Stone, K., Bevilacqua, R. M., Gunson, M. R., Nedoluha, G. and Traub, W. A.

Khattatov, B. V., Lamarque, J.-F., Lyjak, L. V., Ménard, R., Levelt, P., Tie, X., Brasseur, G. and Gille, J. C.

Levelt, P. F., Khattatov, B. V., Gille, J. C., Brasseur, G. P., Tie, X. and Waters, J. W.

Lin, S.-J. and Rood, R. B.

Marsh, D., Smith, A., Brasseur, G., Kaufmann, M. and

Grossman, K.

Ménard, R. and Chang, L. P.

Ménard, R., Cohn, S. E., Chang, L. P. and Lyster, P. M.

Mengistu Tsidu, G., Stiller, G. P., von Clarmann, T., Funke, B., Fischer, H., Glatthor, N., Grabowski, U., Höpfner, M., Kellmann, S., Kiefer, M., Linden, A., Milz, M., Steck, T. and Wang, D. Y.
2005 Retrieval of stratospheric $\mathrm{NO}_{x}$ from 5.3 and $6.2 \mu \mathrm{m}$ non-LTE emissions measured by MIPAS on ENVISAT. J. Geophys. Res., 110(D9), D09302, doi: 10.1029/2004JD005225

2005 Mixing processes during the Antarctic vortex split in September/October 2002 as inferred from source gas and ozone distributions from MIPAS/ENVISAT. J. Atmos. Sci., 62(3), 787-800

1996 Validation of nitric oxide and nitrogen dioxide measurements made by the Halogen Occultation Experiment for the UARS platform. J. Geophys. Res., 101(D6), 10241-10266

1991 Ozone and other trace gases in the Arctic and Antarctic regions: Three-dimensional model simulations. J. Geophys. Res., 96, 2995-3011

1996 A validation of measurements of water vapor from the Halogen Occultation Experiment, HALOE. J. Geophys. Res., 101(D6), 10205-10216

Assimilation of sattelite observations of long-lived chemical species in global chemistry transport models. J. Geophys. Res., 105(D23), 29135-29144

Assimilation of MLS ozone measurements in the global threedimensional chemistry transport model ROSE. Geophys. Res. Lett., 25(24), 4493-4496

1996 Multidimensional flux form semi-Lagrangian transport schemes. Mon. Weather Rev., 124, 2046-2070

2001 The existence of a tertiary ozone maximum in the high-latitude middle mesosphere. Geophys. Res. Lett., 28, 4531-4534

2000 Assimilation of stratospheric chemical tracer observations using a Kalman filter. Part II: $\chi^{2}$ validated results and analysis of variance and correlation dynamics. Mon. Weather Rev., 128, 2672-2686

2000 Stratospheric assimilation of chemical tracer observations using a Kalman filter. Part I: Formulation. Mon. Weather Rev., 128, 2654-2671

$2005 \mathrm{NO}_{y}$ from the Michelson Interferometer for Passive Atmospheric Sounding on the Environmental Satellite during the southern hemisphere polar vortex split in September/October 2002. J. Geophys. Res., 110(D11), D11301, doi: $10.1029 / 2004 J D 005322$ 
Park, J. H., Russell III, J. M., Gordley, L. L., Drayson, S. R., Benner, D. C.,

McInerney, J. M.,

Gunson, M. R., Sen, G. G. B., Blavier, J.-F., Webster, C. R., Zipf, E. C., Erdman, P., Schmidt, U. and Schiller, C.

Ridolfi, M., Carli, B., Carlotti, M., von Clarmann, T.,

Dinelli, B. M., Dudhia, A., Flaud, J. M., Höpfner, M., Morris, P. E., Raspollini, P., Stiller, G. and Wells, R. J.

Riishøgaard, L. P.

Rose, K. and Brasseur, G.

Russell III, J. M., Deaver, L. E., Mingzhao, L., Park, J. H., Gordley, L. L., Tuck, A. F., Toon, G. C., Gunson, M. R., Traub, W. A., Johnson, D. G., Jucks, K. W., Murcray, D. G., Zander, R., Nolt, I. G. and

Webster, C. R.

Sander, S. P., Friedl, R. R.,

Ravishankara, A. R.,

Golden, D. M., Kolb, C. E.,

Kurylo, M. J., Huie, R. E.,

Orkin, V. L., Molina, M. J.,

Moortgat, G. K. and

Finlayson-Pitts, B. J.

Snoeij, P., Koopman, R.,

Wursteisen, P., Zehner, C. and Attema, E.

Steck, T. and von Clarmann, T.

Stiller, G. P., von Clarmann, T., Funke, B., Glatthor, N., Hase, F., Höpfner, M. and Linden, A.

Swinbank, R. and O'Neill, A.
1996

Validation of the Halogen Occultation Experiment $\mathrm{CH}_{4}$ measurements from the UARS. J. Geophys. Res., 101(D6), 1018310203

2000 Optimized forward model and retrieval scheme for MIPAS nearreal-time data processing. Appl. Opt., 39, 1323-1340

1998 A direct way of specifying flow-dependent background error correlations for meteorological analysis systems. Tellus, 50A, $42-57$

1989 A three-dimensional model of chemically active trace species in the middle atmosphere during disturbed winter conditions. J. Geophys. Res., 94, 16387-16403

1996 Validation of hydrogen chloride measurements made by the Halogen Occultation Experiment from the UARS platform. J. Geophys. Res., 101(D6), 10241-10266

'Chemical kinetics and photochemical data for use in atmospheric studies'. Evaluation No. 14, JPL Publication 02-25. California Institute of Technology, Pasadena, USA.

http://jpldataeval.jpl.nasa.gov/download.html

'The ENVISAT Atmospheric Chemistry Instrument Validation Programme'. Proceedings of the Second Workshop on the atmospheric chemistry validation of ENVISAT; Frascati, Italy, 3-7 May 2004. ESA SP-562,

http://envisat.esa.int/workshop/acve2/papers/EGE01PS.pdf

2001 Constrained profile retrieval applied to the observation mode of the Michelson Interferometer for Passive Atmospheric Sounding. Appl. Opt., 40(21), 3559-3571

2002 Sensitivity of trace gas abundances retrievals from infrared limb emission spectra to simplifying approximations in radiative transfer modelling. J. Quant. Spectrosc. Radiat. Transfer, 72, 249-280

1994 A stratosphere-troposphere data assimilation system. Mon. Weather Rev., 122, 686-702 